\title{
Metáforas e metonímias conceptuais do campo léxico- semântico da "corrupção" nas charges políticas
}

\section{Conceptual metaphors and metonymies from the lexical- semantic field of "corruption" in political charges}

Tânia Mara Miyashiro Sasaki ${ }^{1}$

https://orcid.org/0000-0001-7866-0592

Aparecida Negri Isquerdo ${ }^{2}$

https://orcid.org/0000-0003-1129-5775

Resumo: A partir do duplo sentido das palavras determinados pelo contexto, questiona-se sobre como as pessoas usam e compreendem (ou não) as palavras manifestadas de forma criativa. Esta proposta orienta-se pela hipótese de que, para usar e compreender as palavras que possuem variados sentidos, lança-se mão de mecanismos das metáforas e metonímias conceptuais. Investiga-se o papel desses mecanismos cognitivos contidas em cinco charges divulgadas em jornais online e blogs políticos que fazem referência à palavra corrupção. A fundamentação teórica e metodológica tem bases na Linguística Cognitiva, especificamente, nos estudos de Lakoff e

\footnotetext{
${ }^{1}$ Universidade Federal do Mato Grosso do Sul. E-mail: tania.mms@hotmail.com

${ }^{2}$ Universidade Federal do Mato Grosso do Sul. E-mail: aparecida.isquerdo@gmail.com
} 


\begin{abstract}
Johnson (1980), Lakoff (1987), Geeraerts (2010), Kovecses (2015). A metodologia consistiu na verificação inicial de uma linguagem que demonstrasse duplo sentido e do tema que representasse o conceito de corrupção. Procedeu-se para a verificação dos critérios de sistematicidade e coerência cultural e, consequente classificação dos tipos e modelos metafóricos e metonímicos das charges selecionadas. A análise das charges revelou a presença de alguns dos tipos e modelos metafóricos e metonímicos propostos por esses autores e os resultados demonstram que, o uso e a compreensão de palavras com duplos sentidos provêm, principalmente, das conceptualizações oriundas das experiências cotidianas e das vivências culturais de uma comunidade linguística.
\end{abstract}

Palavras-chave: Metáforas e metonímias conceptuais; categorização; linguística cognitiva; corrupção.

Abstract: Based on the double meaning of words determined by context, the question that arises is about how people (do or don't) use and understand words that are expressed in a creative way. This proposal is guided by the hypothesis that, in order to use and understand words with several meanings, conceptual metaphors and metonymies are used. It is investigated the role of these cognitive mechanisms in five political charges that refer to the word corruption. The theoretical and methodological foundations are based on Cognitive Linguistics' contribution, more specifically on studies by Lakoff and Johnson (1980), Lakoff (1987), Geeraerts (2010), Kovecses (2015). The methodology consists of initial verification of language that would have shown double meaning and represented the concept of corruption. Next, the systematic and cultural coherence were verified, followed by classification of metaphorical and metonymical types and models of selected charges. Analysis of charges revealed the presence of some metaphorical and metonymical models and types proposed by these authors and results show that use and understanding of words with double meaning primarily come from conceptualizations based on everyday cultural experiences of a linguistic community.

Keywords: Metaphors and Conceptual Metonymies; categorization; cognitive linguistics; corruption.

\title{
Introdução
}

Através de um olhar mais atento acerca do uso do léxico pelos falantes da língua, é perceptível os diferentes significados adquiridos. Para tanto, um dos recursos empregados para as diferentes manifestações é o uso figurado das palavras, pois, através do conhecimento da estética da linguagem, pode-se explorar novos sentidos num texto escrito e falado, de criar novas perspectivas para o significado das palavras e assim, abre-se as possibilidades de se ver o mundo de outras maneiras.

A questão a ser pesquisada emergiu por meio de observações sobre os diferentes polos da significação e da compreensão lexical, bem como sobre o uso do jogo de palavras. Percebese que existe um ponto em comum nos diferentes usos: o duplo sentido das palavras determinados pelo contexto. Então, a partir dessa percepção, a questão que emerge é sobre como as pessoas usam e compreendem (ou não) as palavras que adquirem outros sentidos.

A partir desse cenário, instigou-se a vontade de se aprofundar na questão das palavras 
que possuem duplo sentido e que causam grande impacto pela criatividade. Muitos indivíduos, ao entrarem em contato com notícias cotidianas e também com críticas manifestadas em charges ou ironias em músicas, parecem não compreender a totalidade ou a essência da mensagem. Por outro lado, existem os indivíduos que parecem ser ricos em criatividade para passar mensagem usando uma palavra que assume outro significado e causa grande impacto pela sua expressividade. Para esta proposta, considera-se o uso criativo das palavras e de como elas são exploradas em certos contextos para atender propósitos comunicativos, ou seja, para identificar e criticar alguns fatos e pessoas da atualidade.

Por uso criativo, consideram-se as formas lexicais que se manifestam pelo seu uso metafórico e metonímico. Pode-se pensar que metáfora e metonímia sejam uma questão de uso de palavras auxiliares para se potencializar a expressividade e que seja possível comunicar sem elas. Entretanto, as metáforas e metonímias vão além da função de operarem como recursos estilísticos da linguagem, as quais adquirem inúmeras interpretações e sensações na comunicação.

Para esse estudo, investigou-se o papel da metáfora e metonímia conceptual, pelo aporte da Linguística Cognitiva. Lakoff e Johnson (1980) afirmam que a metáfora é parte integrante de nossa vida cotidiana, não somente pela linguagem, mas pelos pensamentos e ações. O nosso sistema conceptual é fundamentalmente metafórico, o que indica que nossos pensamentos e ações são metafóricos por natureza, operam nos conceitos e os refletem na linguagem. A justificativa da pesquisa baseia-se na hipótese de que, para usar e compreender as palavras que possuem duplo sentido, lançamos mão de mecanismos cognitivos, as metáforas e metonímias conceptuais. A pesquisa fundamenta-se principalmente em Lakoff e Johnson (1980), Lakoff (1987), Kovecses (2015).

\section{Bases teóricas e metodológicas}

Para se situar no âmbito do surgimento da Linguística Cognitiva, destacamos duas correntes científicas antecessoras e dominantes no século XX. Delimitando-se à fase dos modernos estudos sobre a linguagem, no início do século XX, Ferdinand de Saussure marca um período em que a ênfase para o modelo científico é a descrição das estruturas das línguas, com grande destaque para o estudo do significante do signo linguístico. Para o Estruturalismo, a concepção da linguagem segue o princípio de que a língua deve ser estudada em si mesma e por si mesma. Costa (2008) explica que, a corrente caracteriza-se como um estudo imanente da 
língua e que toda a preocupação extralinguística deve ser abandonada; então, exclui-se, todas as conexões da língua com a sociedade, com a cultura, com a distribuição geográfica e com a literatura. Enfim, exclui-se qualquer relação que não mantenha uma ligação com a organização interna dos elementos constituintes do sistema linguístico.

Outra corrente dominante no século XX é o Gerativismo, corrente que surge a partir dos trabalhos de Noam Chomsky. Para o Gerativismo, a linguagem passa a ser parte da mente humana, um dispositivo inato que permite aos humanos desenvolverem uma competência linguística. Essa disposição inata para a competência linguística é a faculdade da linguagem.

Silva (1997) descreve a relação dessas duas correntes antecessoras e da maneira pela qual se opõem à Linguística Cognitiva. É uma relação de oposição aos paradigmas anteriores, pelo fato de que, o Estruturalismo estuda a linguagem como um sistema que se basta por si mesmo e desconsidera os aspectos extralinguísticos. Já o Gerativismo defende que a faculdade da linguagem é um componente autônomo da mente e sua investigação é sobre como essa faculdade mental é adquirida, portanto, o módulo cognitivo da linguagem independe de outros módulos cognitivos, como a percepção, por exemplo. O paradigma científico da Linguística Cognitiva rejeita os princípios de autonomia da linguagem e da perspectiva modelar de cognição, pois seu interesse é pelo conhecimento através da linguagem e investiga a contribuição da linguagem para o conhecimento do mundo.

Assim como outras ciências cognitivas, assume-se que a interação dos indivíduos com o mundo é mediada pelas estruturas mentais; no caso da Linguística Cognitiva, a estrutura pela qual se ocupa é a linguagem. Silva (1997) explica que é através da análise sistemática da estrutura e do uso linguístico que a Linguística Cognitiva encontra os conteúdos da cognição humana que justificam a realidade psicológica dos conteúdos da mente que são expressos através da linguagem. As investigações cognitivas da linguagem põem em voga as correspondências entre o pensamento conceptual, a experiência corporificada e a estrutura linguística e, consequentemente, os conteúdos reais da cognição.

Assim, em oposição a essas duas correntes dominantes anteriormente descritas, a Linguística Cognitiva emerge no final da década de 70 e início da de 80, explicada como

[...] uma abordagem da linguagem perspectivada como meio de conhecimento e em conexão com a experiência do mundo. As unidades e as estruturas da linguagem são estudadas, não como se fossem entidades autônomas, mas como manifestações de capacidades cognitivas gerais, da organização conceptual, de princípios da categorização, de mecanismos de processamento e da experiência cultural, social e individual. (SILVA, 1997, p.59). 
Lakoff e Johnson (1980) retratam que o livro Metaphors we live by, um dos trabalhos ícones da área da Linguística Cognitiva, foi gerado a partir de uma inquietação acerca de como as pessoas compreendem a linguagem e suas experiências. A experiência humana e sua compreensão assumem papel importante na construção da significação. A Linguística Cognitiva, de acordo com esses autores, aborda questões que ultrapassam a linguagem, a verdade e sua compreensão, e atingem questões sobre a significação de nossas experiências cotidianas. A significação, torna-se assim, um fenômeno linguístico de grande relevância, pela sua associação com o conhecimento do mundo.

Sumariamente, as ideias principais da concepção cognitiva da linguagem consistem "na crença da flexibilidade pragmática e contextual do significado, a convicção de que o significado é um fenômeno linguístico que excede as fronteiras da palavra e o princípio de que o significado envolve perspectivação". (GEERAERTS, 2010, p. 203)

Nos primeiros anos de 1880, Michel Bréal inicia o estudo sobre a transformação dos sentidos - a ciência das significações, sendo por ele nomeada como "Semântica". Consideravase então, como um estudo histórico, cuja "tarefa primordial era estudar as mudanças de significado, explorar suas causas, classificá-las de acordo com critérios lógicos, psicológicos ou quaisquer outros, e se possível, formular "leis" gerais e investigar as tendências subjacentes". (ULLMANN, 1964, p.18)

Um século depois, como parte da Linguística Cognitiva, emerge a Semântica Cognitiva, campo no qual a significação da palavra é tratada pela abordagem psicológica e cognitiva. Geeraerts (2010) aponta as principais contribuições da Semântica Cognitiva para o estudo da significação: o modelo dos protótipos na categorização, a teoria conceptual da metáfora e metonímia, os Modelos Cognitivos Idealizados (MCl) e a teoria dos esquemas/ frames.

A categorização é o processo mental que identifica, classifica e nomeia diferentes variedades de entidades que constituem o mundo. Biderman (1998) afirma que o processo de categorização e nomeação através das palavras fundamentam-se em algo muito abstrato, pois trata-se de processos cognitivos. As palavras designam conceitos ao invés de coisas físicas, então a conceptualização é o próprio processo cognitivo. Os princípios que regem o processo de categorização, a economia cognitiva e a percepção da estrutura do mundo, esclarecem a trajetória cognitiva que se concretiza na nomeação.

Lakoff $(1987$, p. 5) afirma que "não existe nada mais básico do que a categorização para nosso pensamento, percepção, ação e fala". Toda vez que raciocinamos sobre os tipos de coisas: objetos, emoções, doenças, ações, qualquer tipo de coisa, estamos aplicando categorias. 
Para a linguagem, o processo de categorização infunde sua relevância pelo fato de que, para falar sobre o mundo e para o mundo, agrupamos um conjunto de objetos que se assemelham, fazemos referência a um conjunto de ações com características similares e qualificamos coisas, pessoas, emoções, sentimentos que compartilham características em comum.

A capacidade cognitiva para realização do processo da categorização, segundo a Linguística Cognitiva se processa baseada nos protótipos, definidos como os exemplares típicos que melhor representam uma determinada categoria. Chega-se à conclusão que as categorias possuem uma estrutura prototípica.

Para a constituição da significação e da estrutura de uma categoria linguística, há de se levar em conta que essa formação depende de certas estruturas de conhecimento sobre o domínio experiencial a que essa categoria está associada. Chama-se isso de modelo cognitivo, quando o conhecimento é individualmente partilhado ou de modelo cultural, quando partilhado por um grupo social.

As categorias são formadas e organizadas pela prototipicidade. Questiona-se então, a razão da relação entre protótipos e os efeitos de prototipicidade e categorias. Silva (1997) descreve a explicação sugerida por Geeraerts (1988), as categorias são cognitivamente eficientes quando estruturadas na base da prototipicidade, pois oferecem as vantagens da flexibilidade e estabilidade. O foco sobre a flexibilidade permite a adaptação aos diversos contextos e também a integração de novas entidades como membros de uma mesma categoria, mesmo que estejam numa posição mais periférica. Já com o foco sobre a estabilidade, permite-se que novas experiências sejam interpretadas, afastando-se a necessidade de criação de novas categorias ou de redefinição dessas já existentes.

Levando-se em conta as vantagens da prototipicidade, percebe-se o sentido do entrelaçamento de suas relações, pois

\footnotetext{
[...] a prototipicidade existe porque é cognitivamente vantajosa, porque satisfaz estas duas tendências, aparentemente contraditórias, da cognição humana. Daí que as categorias linguísticas sejam tipicamente flexíveis e polissêmicas e daí a continuidade e a mutabilidade dos significados das palavras no seu desenvolvimento histórico. (SILVA, 1997, p. 71).
}

A flexibilidade e a estabilidade, tendências relacionadas à categorização que embora possam ser entendidas como contraditórias, respondem bem às palavras que possuem vários sentidos e que têm empregos distintos conforme os diversos contextos. A razão para isso é 
justamente a adaptação para as mudanças de significação que se consegue para as categorias nas diferentes situações ao longo de um período de tempo e a incorporação de novas entidades, tendo como resultado o equilíbrio do número de categorias. Portanto, as tendências que parecem ser aparentemente contraditórias, podem também assumir uma perspectiva de causa e efeito. A estabilidade existe porque ela é resultante da flexibilidade.

Silva (1997) alega que é no contexto desses modelos que se permite que as categorias linguísticas sejam devidamente caracterizadas. Os modelos cognitivos têm limites indeterminados e podem associar-se em redes, por isso, deve ser seletiva pela sua grande abrangência. Outra característica é que um ou mais modelos cognitivos estão envolvidos para qualquer ato de categorização, mesmo os relacionados às situações não muito familiares.

Exemplificando pelo modelo cognitivo de "mãe", segundo Lakoff (1987), esse modelo remete a vários domínios da experiência: de nascimento e genético, nutritivo, educacional, marital e genealógico.

Silva (1997) enfatiza que se compreenda a noção de domínio (domínio cognitivo), proposto por Langacker (1987). Silva (1997, p.83) explica a noção de domínio, trata-se de "qualquer área de conhecimento que serve como base de significação de uma unidade cognitiva que seja linguisticamente expressa". Existem os domínios básicos, que representam a "experiência humana cognitivamente irredutíveis", como o espaço, o tempo, a temperatura etc.; e os domínios complexos, os quais são "caracterizáveis em relação aos domínios básicos", como bidimensional, depois, frio etc.

No prosseguimento dos estudos acerca das estruturas das categorizações e dos efeitos prototípicos, Lakoff (1987) sustenta que o conhecimento é organizado por meio de estruturas chamados de Modelos Cognitivos Idealizados (doravante MCls). O autor defende que as estruturas das categorizações e os efeitos prototípicos são fenômenos originados desses modelos, portanto, são subprodutos dessa organização cognitiva complexa.

Geeraerts (2010) afirma a relevância dos MCls para a Semântica Cognitiva, pelo fato de que

[...] nosso conhecimento da linguagem é intimamente relacionado com nosso conhecimento de mundo, e tal conhecimento assume a forma de modelos cognitivos: conjuntos estruturados de crenças e expectativas que direcionam o processamento cognitivo, incluindo o uso da linguagem. (GEERAERTS, 2010, p. 245).

Então, com a perspectiva de organização de estruturas acerca do conhecimento 
humano, os MCls destacam três aspectos importantes dessas estruturas cognitivas: elas são idealizadas, são cognitivas e são modelos. McCauley $(1987$, p. 292) elabora uma definição dos MCls da seguinte forma: "Os modelos cognitivos idealizados são construtos mentais simplificados que organizam vários domínios da experiência humana, tanto as experiências práticas, quanto as teóricas".

Através da compreensão dos aspectos dos MCls, obtém-se o melhor esclarecimento dos modelos propostos por Lakoff. Segundo Geeraerts (2010, p. 245), os MCls são chamados de idealizados pela abstração que se faz do mundo real. A complexidade da realidade não é capturada por inteiro, mas através dos MCls, que viabiliza uma matriz para se lidar tal complexidade com flexibilidade.

Com essa possibilidade, esses modelos simplificam o mundo. McCauley (1987) explica que as estruturas são idealizadas pelo fato de que, num grande universo de estímulos que compõem cada contexto, a seleção acontece baseados na eficácia e significação, ou seja, escolhe-se aqueles que são mais eficazes e significantes nos domínios teóricos ou práticos. Ao idealizar, deixa-se de enfatizar ou ignora-se uma outra gama de possibilidades pelo ceteris paribus, os quais, presume-se implicitamente a relativa falta de importância de determinada gama. Os MCls definem uma série de chaves no ambiente que conseguem determinar uma situação e daí, estabelecer expectativas de mudança e respostas apropriadas ao contexto.

Além de idealizados, os MCls são cognitivos. Esses modelos dependem das habilidades imaginativas para se eleger um modelo para um determinado domínio. Dentre os vários membros de uma categoria, alguns são julgados como melhores exemplos dependendo do modelo que se aplica a uma situação particular.

Os MCls são modelos sobre o mundo. Isso quer dizer que a soma de todos esses modelos constitui a superestrutura do conhecimento humano acerca do mundo. A descrição dos MCls, segundo Lakoff (1987), cada um desses modelos é retratado como um todo estruturado, uma gestalt, que se utiliza de quatro tipos de princípios estruturantes:

- estrutura proposicional, como nos frames de Fillmore.

- esquema imagético, como na gramática cognitiva de Langacker.

- mapeamento metafórico, como descrito por Lakoff e Johnson.

- mapeamento metonímico, como descrito por Lakoff e Johnson.

Para esclarecer como cada MCl estrutura o espaço mental, Lakoff (1987) toma o conceito de Fillmore sobre o conceito de frame. Exemplificado pela palavra terça-feira, que 
pode ser definida somente relativo a um modelo idealizado. Esse modelo inclui o ciclo natural definido pelo movimento do sol, que é a maneira padronizada de se caracterizar o fim de um dia e início do próximo. Perfaz um ciclo do calendário de sete dias, a semana. No modelo idealizado, a semana é um total de sete partes organizada em uma sequência linear, cada parte é chamado de dia e o terceiro dia é terça-feira. Da mesma forma, o conceito de fim de semana, requer a noção de uma semana de cinco dias de trabalho seguido de um descanso de dois dias, sendo estabelecido pelo calendário de sete dias.

Conclui-se então que o modelo da semana é idealizado porque a semana de sete dias não existe objetivamente na natureza, pois é uma criação dos indivíduos que vivem sob o mesmo sistema cultural da semana de sete dias. Esse modelo, considerado "nosso modelo", difere do sistema calendário balinês. Para a cultura balinesa, requer-se um $\mathrm{MCl}$ complexo que impõe estruturas de três semanas: uma semana de cinco dias, uma de seis dias e uma de sete dias.

\section{Metáforas e metonímias conceptuais}

Aristóteles, em sua obra Arte Poética, já evidenciava a metáfora. Descreve como a transposição do nome de uma coisa para outra e afirma que "descobrir metáforas apropriadas equivale a ser capaz de perceber as relações" (p.37). Relações como na afirmação o que a velhice é para a vida, a tarde é para o dia. Nesta relação entre as palavras velhice, tarde, dia possuem metáforas que são explicadas da seguinte forma: a tarde é a velhice do dia e a velhice é a tarde da vida.

Sabe-se que toda língua passa por uma perpétua transformação que é comprovada por estudos diacrônicos sobre as mudanças semânticas do léxico. São várias palavras que ao longo da história passam a assumir um outro significado, diferentes do significado etimológico.

Bréal ([1897], 1992) no final do século XIX, já discutia a perspectiva das significações, a força do significado das unidades lexicais. Em seus estudos sobre o sentido das palavras, afirma que, uma vez criadas e providas de um certo sentido, as palavras são levadas a restringi-lo ou estendê-lo, a transportá-lo de uma ordem de ideias a outra, a rebaixá-lo ou elevá-lo em dignidade, enfim, a mudar o sentido. No caso da ampliação do sentido, que tem uma causa exterior, é o resultado dos acontecimentos da história, cuja transformação é lenta, involuntária e imperceptível. Entretanto, a metáfora muda instantaneamente o sentido das palavras ao criar expressões novas de modo súbito. Trata-se da visão de similaridade entre dois objetos ou atos e 
preenchimento de uma lacuna no vocabulário, o que faz nascer uma metáfora. Entretanto, ela não permanece da mesma forma em sua criação, pois o uso bem-sucedido a faz empalidecer e se transforma em apenas uma representação da ideia com mais vivacidade que a própria palavra.

Tradicionalmente, as metáforas e metonímias são consideradas como figuras de estilo com a função retórica e ornamentação da linguagem. O conhecimento tradicional que temos acerca das metáforas e metonímias remetem às figuras de linguagem, as quais são usadas para se comunicar com mais expressividade, pois utiliza-se as palavras de forma mais criativa e original. A metáfora proporciona o uso de um termo por outro termo, levando-se em conta a semelhança entre ambos.

Então, pode-se pensar que metáfora e metonímia sejam uma questão de uso de palavras como recursos estilísticos e retóricos para se potencializar a expressividade. Entretanto, através da Semântica Cognitiva, abre-se uma outra perspectiva. A visão é de que as metáforas e metonímias vão além da função de funcionar como figuras de linguagem, pois adquirem um status de fenômeno cognitivo em seu tratamento. Estas metáforas e metonímias, numa perspectiva cognitiva, são consideradas fenômenos conceptuais. Isso quer dizer que os conceitos que se têm sobre a realidade são resultados da experiência e conhecimento individual já existentes em interação com o contexto social, histórico e cultural no qual um indivíduo está inserido.

Lakoff e Johnson (1987) afirmam que a metáfora conceptual é parte integrante de nossa vida cotidiana, não somente pela linguagem, mas pelos pensamentos e ações. O nosso sistema conceptual é fundamentalmente metafórico, o que indica que nossos pensamentos e ações são metafóricos por natureza. Isso se realiza porque "a essência da metáfora é entender e experenciar um tipo de coisa através de outra coisa" (LAKOFF e JOHNSON, 1987, p.5)

Os conceitos que guiam nossos pensamentos não são produtos de nosso intelecto, pois esses conceitos também direcionam nosso funcionamento cotidiano. Ações simples e mesmo as mais criativas, como nomear algo, espontaneamente e descontraidamente, realizam-se através da construção dos conceitos que incorporamos através das experiências individuais. São os conceitos que estruturam a nossa percepção de mundo e de como nos relacionamos com as coisas e pessoas, definindo assim, o perceber, o pensar e o fazer de nossa realidade diária.

Sabe-se que nem sempre somos conscientes do sistema conceitual pela automaticidade que desenvolvemos nas interações. Além disso, as pessoas podem ter a percepção errônea de que todos possuem o mesmo conceito sobre o mesmo referencial. Entretanto, como todas essas ações são fenômenos internos e individuais, que acontecem dentro de nossa mente, a linguagem 
atua como uma fonte importante para evidenciar a descrição do sistema conceitual.

Um exemplo de conceito metafórico citado por Lakoff e Johnson (1980) é: discussão é guerra. O conceito que se tem acerca de discussão como guerra é a semelhança com ações que acontecem nesses contextos. A conceptualização é metafórica pela noção de guerra que temos em nossa mente, mesmo nunca ter realmente participado literalmente dessa experiência.

As expressões do vocabulário para guerra é uma forma sistemática de se falar sobre os aspectos de um debate e adquire-se significado que possuem quando usamos essas expressões para descrever um debate. Utiliza-se de dois domínios (discussão e guerra) para se estabelecer uma analogia das estruturas linguísticas: um ponto de vista que está em conflito (uma luta) que se pode apresentar objeções a uma opinião (atacar), manter uma opinião (defender) ou aceitar uma outra opinião (render-se) entre os participantes (adversários) até que se alcance um acordo (vitória e derrota). As diversas palavras usadas sistematicamente nessa descrição - atacar e defender a ideia, tomar diferentes posições, a estratégia de ataque e defesa - constituem-se como as realizações linguísticas da metáfora conceptual discussão é guerra. As expressões linguísticas evidenciam a conceptualização metafórica, justificado

[...] pelo fato de que as expressões metafóricas em nossa linguagem estão ligados aos conceitos metafóricos de uma forma sistemática, pode-se usar as expressões linguísticas metafóricas para se analisar a natureza dos conceitos metafóricos e assim, obter-se uma compreensão da natureza metafórica de nossas atividades. (LAKOFF E JOHNSON, 1980, p. 7).

Lakoff e Johnson (1980) apontam dois pontos relevantes que envolvem a natureza dos conceitos metafóricos: a sistematicidade e a coerência cultural.

Sistematicidade: o conceito metafórico segue padrões de palavras, portanto, a linguagem é também sistemática. Justifica-se pelo fato de que usamos as expressões linguísticas metafóricas para se estudar esses conceitos e assim, entender a natureza metafórica de nossas atividades. No caso, discussão é guerra, pode-se perceber os padrões linguísticos metafóricos usados para se referir à discussão que coincidem com os padrões para se caracterizar a guerra. Um outro exemplo do conceito metafórico: tempo é dinheiro; pois, utiliza-se as expressões você está gastando meu tempo, a troca de pneus me custou uma hora, eu perdi muito tempo quando fiquei doente.

Coerência cultural: considerando que os nossos valores estão vinculados em nossa cultura, em relação a que é importante para o grupo e significativo para a maioria. Estes valores formam um sistema coerente com os conceitos metafóricos do cotidiano de uma cultura. $\mathrm{O}$ 
conceito "você terá um maior status no futuro", provém da ideia de que maior é melhor, maior status é estar acima e o futuro é estar melhor.

Através dos exemplos citados, pode-se perceber que a metáfora envolve a analogia entre dois domínios da experiência; no caso exemplificado anteriormente, da metáfora estrutural - discussão é guerra, o domínio da guerra e o domínio da discussão. Torna-se claro que a analogia que surge entre os dois domínios

[...] mostram que a metáfora não é uma mera extensão (ou transferência) semântica de uma categoria isolada para outra categoria de um domínio diferente, mas envolve uma analogia sistemática e coerente entre a estrutura interna de dois domínios da experiência e, consequentemente, todo o conhecimento relevante associado aos conceitos e domínios em causa. (SILVA, 1997, p. 75).

As metáforas conceptuais diferenciam-se pelas formas que atuam no sistema conceptual. Lakoff e Johnson (1980) descrevem alguns tipos de metáforas de destaque que permeiam nosso dia-a-dia.

As metáforas orientacionais organizam todo o sistema de conceitos ao tratar de um conceito pelo outro. A base para essa organização é a experiência corporal e cultural que vivenciamos, pois essas metáforas fornecem o conceito de orientação espacial que o corpo humano assume em suas ações no espaço físico.

As metáforas ontológicas são relacionadas a entidades e substâncias abrem a perspectiva para a compreensão das experiências de forma que é possível categorizá-las, agrupá-las e quantificá-las. Dessa maneira, abre-se um olhar para as experiências (como os eventos, as atividades, as emoções, as ideias, etc.) em termos de entidade, representando algo que possui vida ou poder e substância, para a representação das coisas que se relacionam com os limites de nosso corpo e com o resto do mundo que está fora do corpo.

Usando-se a personificação, como uma metáfora ontológica, é possível que se compreenda a experiência com entidades não humanas recebendo o tratamento semelhante a de um ser humano que possui motivações, características, atividades, etc. Alguns exemplos de expressões corriqueiras: a vida me enganou, essa teoria explica o comportamento em questão, a religião diz que que não se pode beber vinhos franceses.

As metáforas estruturais permitem o uso de conceito altamente estruturado e claramente delineado para se estruturar um outro conceito. Essas metáforas estão baseadas nas correlações sistemáticas que fazem parte de nossa experiência, portanto, estão pautados nas 
vivências físicas e culturais. Tomando o conceito metafórico, o tempo é um recurso, pode-se observar que esta metáfora está culturalmente embasada em nossa experiência como um recurso material, que pode ser matéria-prima ou fonte de energia. Sendo assim, esse recurso material é um tipo de material que pode ser quantificado, tem um valor em quantidade, tem um propósito para ser consumido e é usado progressivamente. Essa metáfora não pode ser considerada universal, pois é aceitável e compreendida somente nas sociedades em que o tempo é valorizado pela forma de se encarar os propósitos que se deseja alcançar, ou seja, ela enfatiza o valor principal de nossa cultura.

Lakoff e Johnson (1980) operam o destaque para a relação entre a metáfora, a corporificação e a cultura para a estruturação da metáfora conceptual. Kovecses (2015) baseado em suas pesquisas sobre emoções, assevera que "quando as pessoas metaforicamente conceptualizam um domínio em uma situação ela está sob a 'pressão da coerência'" (KOVECSES, 2015, p. 93).

Conforme Kovecses (2015), a pressão que se salienta origina-se do corpo humano e do contexto local e global, sendo que, uma metáfora bem-sucedida emerge quando existe a coerência em ambas as pressões. Esta questão demonstra que, tanto o corpo, quanto o contexto tem papéis relevantes para que uma metáfora possa emergir.

Uma metáfora considerada genérica, ou seja, universal, e motivada pela experiência corpórea, terá distinções pelos seus detalhes influenciados pela variação cultural. Isso quer dizer que quando se tem a confluência da pressão provinda do contexto e da experiência corpórea, estamos lidando com a metáfora corpórea baseada no construcionismo.

Pode-se, então, encontrar a universalidade e a variação em uma mesma metáfora. Pelo exemplo da metáfora: uma pessoa brava é um recipiente pressurizado, pode ser que a pressão venha por causa de um líquido ou gás, pode também ser que o recipiente seja uma parte do corpo, como o estômago ou a cabeça e não o corpo inteiro, pode também se referir à respiração ou palavras que ficam contidas. Enfim, pode-se ter diferentes respostas para essa experiência corpórea. Na cultura brasileira, a expressão - estou fervendo de raiva - bem atende a essa metáfora citada pelo autor, a experiência corpórea da raiva como um conteúdo líquido dentro do próprio corpo que está em turbilhão.

Uma metáfora pode também ser motivada apenas pela experiência corpórea, chamada de metáfora com base corpórea, que indica que esse tipo de metáfora independe da cultura. Através da metáfora, saber é ver, percebe-se a universalidade dessa motivação, pois pode-se descobrir algo pela habilidade de se enxergar.

Num outro extremo, temos a metáfora predominantemente fundamentada na cultura, 
a chamada metáfora com base cultural, exemplificado por tempo é dinheiro. A metáfora baseada nas sociedades onde o capitalismo prevalece e todo o tempo é dimensionado em termos de produção visando a lucratividade.

A variação das bases das metáforas conceptuais que Kovecses (2015) aponta abre-se para uma visão amplificada da cultura e do contexto. Demonstra que a base da construção da significação das metáforas tem uma gradiência que se diversifica tomando-se por base a universalidade da corporificação, a variação das tendências contextuais culturais ou a combinação das duplas motivações.

Levanta-se a questão sobre a estruturação do sistema metafórico, Lakoff e Johnson (1980, p. 56), afirmam que "a maioria do nosso sistema conceptual cotidiano é metaforicamente estruturado". Essa afirmação leva à conclusão de que a maioria dos conceitos que as pessoas têm sobre as coisas são compreendidas em termos de outros conceitos.

Lakoff e Johnson (1980) descrevem que a metonímia conceptual se baseia na relação de contiguidade com função referencial ao usar uma entidade para se referir a uma outra que tenha relação a ela. Além da função referencial, possui também a função de proporcionar a compreensão, pois a partir de um todo, utiliza-se a parte de maior destaque para determinar especificamente o aspecto que se pretende focar. Por exemplo, escolhe-se uma parte do todo que represente uma pessoa cuja característica principal é a inteligência, com a qual relacionase com a cabeça. Então, é comum a expressão: precisamos das melhores cabeças; quer dizer, o requisito inteligência é a necessidade em questão.

Para os autores Lakoff e Johnson (1980), essas funções metonímicas conceptuais, similares às metáforas conceptuais, funcionam ativamente em nossa cultura e o embasamento ocorre também a partir da experiência. Um ponto diferencial entre a metáfora e metonímia é que a fundamentação dos conceitos metonímicos se demonstra mais óbvia, pois o embasamento envolve associações diretas físicas e causais.

Como explanado por Lakoff (1987), um outro ponto de semelhança com as metáforas conceptuais é a sistematicidade que as metonímias conceptuais também seguem, pois não são ocorrências arbitrárias e fazem parte de nosso cotidiano pelos exemplos representativos existentes em nossa cultura. Quando se depara com exemplos de conceitos metonímicos gerais, percebe-se que esses conceitos organizam e afetam nossos pensamentos e ações. Um exemplo usado por Lakoff (1987) para metonímia Nixon bombardeou Hanoi. Este exemplo indica a natureza metonímica - o controlador (Nixon que tem o poder) pelo controlado (a pessoa que foi responsável por soltar a bomba no sentido literal). O próprio Nixon não bombardeou Hanoi, mas esse bombardeio estava sob sua responsabilidade. Então, por esse exemplo, percebe-se que 
o efeito sobre nosso pensamento, raciocina-se que a responsabilidade sobre Hanoi, não está no controlado e sim no controlador.

Resumidamente, Geeraerts (2010) demonstra os quatro pontos de semelhanças que Lakoff e Johnson (1980) enfatizam acerca das metáforas e metonímias que lhes dão o estatuto de conceptual e não puramente linguístico:

1. Como os conceitos metonímicos permitem que se pense sobre uma determinada coisa em termos de relação com outra coisa, pode-se distinguir a fonte e o alvo, quer dizer que os domínios que dão origem e desígnio são claramente identificáveis.

2. Existe a sistematicidade nas metonímias, pois essas formam padrões que se aplicam além de apenas um item lexical.

3. As metonímias conceptuais estruturam não somente nossa linguagem, como também nossos pensamentos, atitudes e ações.

4. O embasamento dos conceitos ocorre a partir da experiência.

Como definido por McCauley (1987), os Modelos Cognitivos Idealizados (MCls) são os construtos mentais simplificados com a função de organizar os domínios das nossas experiências práticas e teóricas. Lakoff (1987) lista alguns casos representados pelos modelos metonímicos, seguindo a teoria dos modelos cognitivos, pelos quais a metonímia é uma das principais fontes dos efeitos prototípicos. Segundo o autor, os modelos metonímicos possuem as seguintes características:

- o alvo do conceito A deve ser compreendido dentro de um certo contexto.

- existe uma estrutura conceptual contendo dois conceitos: A e B.

- B é parte do A, ou está relacionado fortemente com a estrutura conceptual. Uma escolha do $\mathrm{B}$ determinará $\mathrm{O} \mathrm{A}$.

- quando comparado ao A, o B é mais facilmente compreensível ou mais útil dependendo do propósito.

- o modelo metonímico mostra a forma que A e B estão relacionados, cuja relação é especificada por uma função do B para o A.

Lakoff (1987) relaciona alguns modelos metonímicos a partir dos efeitos prototípicos da metonímia:

Estereótipos sociais: um dos tipos dos modelos usados para representar uma categoria 
como um todo. Usa-se para raciocinar sobre algo, caracterizar expectativas sociais e tirar conclusões. Acontecem de forma geralmente consciente e podem estar sujeitos às discussões públicas. O estereótipo dos políticos é de ser conivente, egoísta e desonesto. Pode-se também dar nomes para os estereótipos: Tio Patinhas, cujo estereótipo é de ser uma pessoa que detesta gastar dinheiro e adora economizar.

Exemplos típicos: modelo que se caracteriza pela inconsciência, pela automaticidade em seu uso, pela não sujeição às discussões em público e pela aparente estabilidade durante a vida de uma pessoa. São usados para raciocinar sobre algo e não para definir uma experiência cultural. Maçãs e a laranjas são as frutas típicas. Quando se organiza a maioria do conhecimento sobre categorias (no caso, a categoria das frutas), isso acontece em torno dos casos típicos (maçãs e laranjas).

Ideais: organizam o conhecimento cultural, o que direciona para os efeitos prototípicos. Os julgamentos de qualidade são organizados em torno dos ideais: casamento ideal, família ideal, emprego ideal, aluno ideal, etc.

Padrões: modelo que representa indivíduos ideais ou o seu oposto. A representação é feita baseada no modelo de beleza, de conduta, de desempenho, enfim, de diversos padrões de grande significação dentro de um contexto cultural. Quando se faz o uso de estruturas linguísticas para se referência a alguém ou a alguma coisa é comum as expressões: um outro Trump, ele é o Bolt da banda. Utiliza-se esse modelo como base nas ações com a finalidade de vivenciar esses padrões. Viajar para os lugares considerados as Sete Maravilhas do Mundo.

Geradores: modelo constituído pelos membros que são gerados a partir de um membro central. Exemplificado pelos números naturais, de 0 a 9 , esses geram os números racionais e os reais.

Submodelos: modelo que se constitui fazendo-se referência às aproximações e estimativas de tamanho, mostrando os efeitos prototípicos, por exemplo: a afirmação - 98 é aproximadamente 100. Aplicados também aos submodelos de base biológica como às cores primárias, às emoções básicas, etc.

Exemplos salientes: tipo de modelo que as pessoas usam exemplos que são salientes por ser familiar ou memorável. Para se referir à categoria dos desastres naturais, o exemplo saliente é o furacão Katrina, à categoria das tragédias ambientais, outro memorável é a tragédia de Mariana. Na categoria de histórias marcantes nos esportes, o memorável 7 x1 no jogo Brasil e Alemanha na Copa do Mundo de 2014.

Através dos modelos metonímicos apresentados, pode-se compreender o status cognitivo usados para se raciocinar sobre algum conceito. 


\section{Análise}

Para a análise dos modelos metafóricos e metonímicos, buscou-se charges disponibilizadas online em sites de humor político e blogs com conteúdos que, ironicamente criticam personalidades e fatos atuais. De acordo com o jornal O Estadão, corrupção foi a palavra eleita do ano de 2017 no Brasil, por refletir o ethos e apreensão da sociedade brasileira. Considerando que, palavras retratam o espírito de uma época, para a constituição do corpus de estudo, o critério seletivo principal que orientou o trabalho, foram as referências metafóricas e metonímicas a esse campo léxico-semântico manifestadas nas charges. Mais especificamente, os parâmetros para a seleção foram: a existência de palavras com duplos sentidos determinados pelo contexto em seus curtos diálogos, palavras ou expressões que causam impacto pelo uso criativo e que tivessem elementos linguísticos que expressassem as metáforas e metonímias conceptuais com elementos que fossem contemporâneas e familiares ao nosso cotidiano.

A partir da seleção das cinco charges que possibilitam descrever e analisar diferentes conceitos propostos por Lakoff e Johson (1980), Lakoff (1987) e Kovescses (2015), a análise seguiu os critérios que caracterizam a natureza das metáforas e metonímias, ou seja, procedeuse para a verificação dos critérios de sistematicidade e coerência cultura, seguida pela classificação dos tipos e modelos metafóricos e metonímicos das charges selecionadas.

Na situação descrita na Charge 1, há um médico que dá o diagnóstico de virose a um enfermo. A pessoa doente pensa que está com dengue, mas o diagnóstico verdadeiro é a corrupção. Sabe-se que a virose é uma doença causada por um vírus, um micro-organismo acelular infeccioso; já a corrupção é todo ato de desvio de recursos, de suborno, de furto em benefício próprio e prejuízo para o Estado (Dicionário Caldas Aulete).

Como explicado por Lakoff e Johnson (1980), a metáfora estrutural possibilita que se use a estrutura de um conceito bem delineado, para se estruturar um outro conceito. Neste caso, o conceito de virose é rapidamente compreendido e pode-se fazer as correlações sistemáticas com o conceito de corrupção dentro de nossa experiência porque a metáfora é construída dentro do sistema conceitual de nossa cultura.

Sabe-se que a virose é uma doença infecciosa, causada pela contaminação direta com ambientes ou com pessoas infectadas. Uma vez infectado, o corpo enfraquece e sofre pelas dores em determinadas regiões do corpo e perda de líquidos. Seguindo a sistematicidade e coerência (LAKOFF E JOHNSON, 1980), que são os pontos relevantes que envolvem a natureza dos conceitos metafóricos, percebe-se os padrões de palavras existentes nos dois domínios da experiência. A corrupção é um mal causado ao nosso país, que infecta as pessoas que entram 
em contato direto com as pessoas e lugares contaminados, situação que provoca dores em várias partes do país, pois a população é usurpada de seus direitos para o bom funcionamento dos órgãos, ou seja, das instituições que garantem qualidade de vida para a população.

Outra metáfora presente na charge é a personificação, pois retrata-se o Brasil como uma pessoa que está com o corpo abalado, estremecido por uma doença. Kovecses (2015) evidencia que uma metáfora bem-sucedida atende à pressão da coerência provindas do corpo humano e do contexto. Neste caso, a metáfora relacionada à corporificação e à cultura fazem a estruturação dos conceitos presentes nos domínios da experiência. Segue a relação do corpo humano e do contexto local, pois os brasileiros têm experenciado a corrupção como uma doença de forma tão revoltante e dolorida por um longo tempo; ambas as experiências são indesejáveis.

Fig.1 - Metáfora: Corrupção é uma doença infecciosa no Brasil.

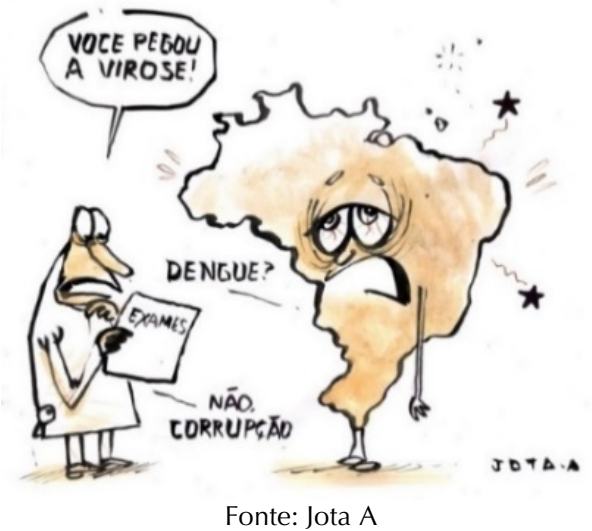

Segundo informações do Ministério de Segurança Pública, dentre as várias competências da Polícia Federal, uma delas é de "apurar infrações penais praticadas em detrimento de bens, serviços e interesses da União ou de suas entidades autárquicas e empresas públicas" (BRASIL, 2018). Para se obter maior compreensão da situação descrita na Charge 2, a partir da visão de um corrupto e de um advogado, utilizou-se nesta charge o conceito de madrasta para referir à Polícia Federal e de mãe para aludir à Justiça Federal. O conceito de madrasta como estereótipo tem um valor depreciativo no consciente coletivo, pois trata-se de uma mulher que se tornou a nova companheira do pai, tomou o lugar da mãe e que possui um comportamento perverso no tratamento dos filhos. Como descrito por Lakoff (1987), dentre os vários modelos cognitivos idealizados ( $\mathrm{MCls}$ ) existentes, os modelos empregados foram o de 
mãe protetora e madrasta perversa.

Lakoff e Johnson (1987) explicam que é pela metáfora conceptual que se entende e se experencia uma coisa em termos de outra. Isso é verdadeiro na experiência que o corrupto e o advogado vivenciam com as instituições judiciais em diferentes âmbitos. Pelo mecanismo cognitivo, a linguagem possibilita a compreensão da vivência do corrupto diante do comportamento cruel da Polícia Federal, pois esta instituição é responsável de se restringir a liberdade para a prática dos atos ilícitos e de se estabelecer a ordem no país. Já para o advogado o tratamento que recebe da Justiça é de uma mãe. A associação é direcionada para o modelo de mãe como a uma pessoa que deu à luz e é dadivosa. Explica-se seus pensamentos e atitudes do advogado pela sua linguagem, pois é através do sistema da Justiça Federal que se gerou uma fonte generosa de renda para a defesa dos corruptos pela atual situação do país.

Charge 2 - Metáfora: Justiça no Brasil é mãe e madrasta.

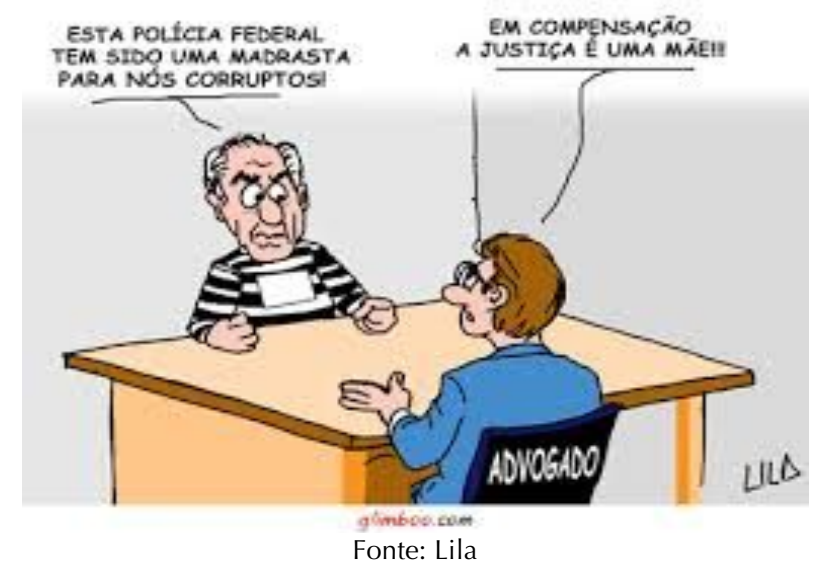

Na charge 3, um motorista pede informação sobre a localização espacial do Congresso. Sabe-se que o Congresso Nacional é o prédio onde se legisla sobre os assuntos de nosso país, por meio da Câmara dos Deputados e Senado Federal.

A pessoa que passa a informação sobre a localização, responde utilizando-se de uma metáfora conceptual, proposto por Lakoff e Johnson (1987), a qual nos permite entender alguma coisa através de outra coisa. No caso, da resposta dada, foi possível compreender o conceito realizado pela linguagem que o pedestre tem sobre o Congresso Brasileiro.

Utilizou-se a personificação para expressar o conceito acerca de um local (prédio), ou seja, uma entidade não humana. Através desse mecanismo cognitivo, faz-se emergir algumas características humanas: a ética, a decência, a honestidade, como mencionadas na charge. Além 
disso, a metáfora conceptual mostra, mais especificamente, que o Congresso é uma pessoa que apresenta atitudes de distanciamento da decência, da honestidade, da ética da falta de interação com outras pessoas e que não valoriza a moralidade. Todos esses itens encontram-se muito afastados desta pessoa.

Charge 3 - Metáfora: O Congresso Brasileiro é uma pessoa que tem déficit de valores e princípios morais.

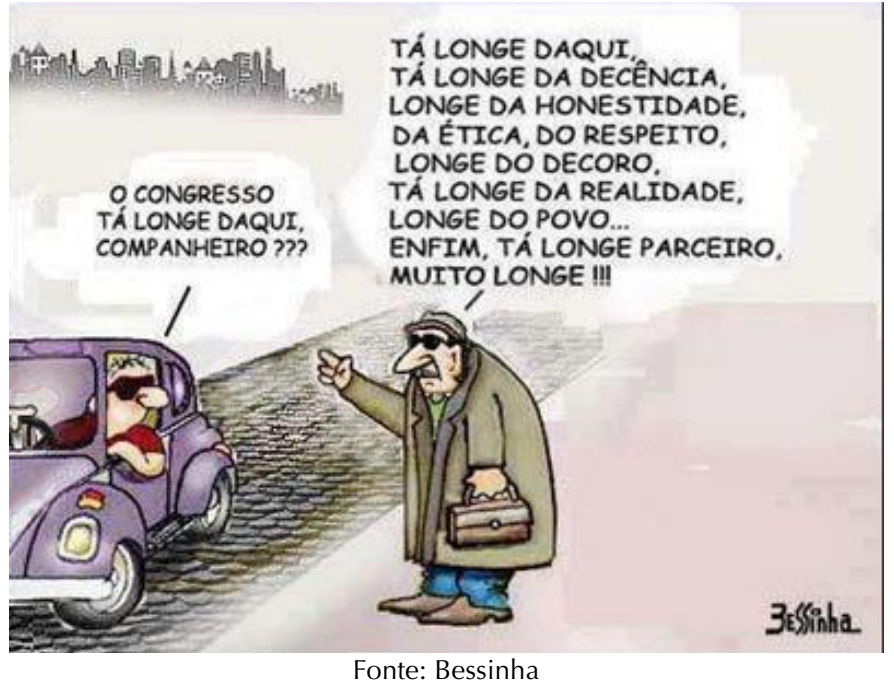

Entende-se por político uma pessoa que exerce ou está disposto a assumir um cargo eleitoral para lutar pelos interesses do povo. No entanto, pela vivência política, social e cultural que o povo brasileiro tem experenciado nos últimos anos, o conceito que se adquiriu de político tem um valor pejorativo. Esse conceito remete ao referencial de ser uma ser uma pessoa egoísta, ou seja, aquele que age para atender somente seus próprios interesses e de ser desonesto, pois pratica atos ilícitos para se apoderar do dinheiro público.

Lakoff e Johnson (1980, p. 39) afirmam que, "as metáforas, os conceitos metonímicos estruturam não somente nossa linguagem, mas também nossos pensamentos, atitudes e ações". $\mathrm{Na}$ Charge 4, dois meninos estão em confronto e percebe-se que um deles está buscando palavras que expressem sua indignação com o outro. Na tentativa de encontrar a melhor palavra para ofender o outro, "seu.. seu...", ele se expressa pelo "seu político", o que prontamente remete o leitor ao entendimento de causação de ofensa. O modelo metonímico empregado foi o de estereótipo social (Lakoff, 1987), pois utilizou-se do modelo do político para se referenciar às suas características mais marcantes, de ser egoísta e desonesto. A referência é o conjunto de características negativas para atingir o efeito da ofensa que causa em outra pessoa, usou-se a 
palavra político com um xingamento.

O modelo metonímico de estereótipo social, que provém dos efeitos prototípicos, representa a maneira que a categorização acontece por meio dos protótipos, pois reúne-se o conjunto de características que se aproximam do modelo mais saliente do protótipo da categoria para se falar sobre as coisas do mundo. No caso da charge, reuniu-se na categoria do modelo do político algumas imagens que o retratem implicitamente e negativamente.

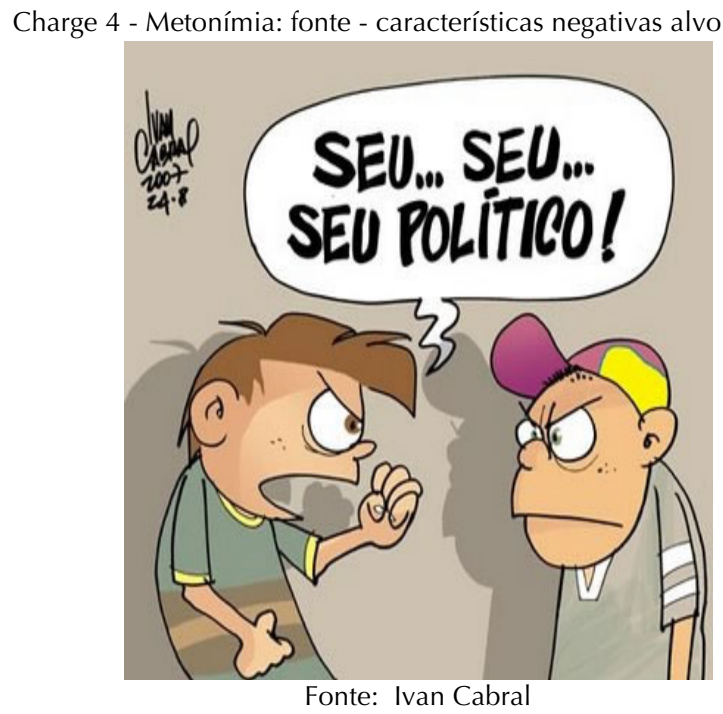

Desde 2014, o Brasil tem presenciado o desenrolar de uma grande investigação envolvendo executivos da Petrobrás, empresa brasileira para a extração de petróleo, grandes empresários de empreiteiras e políticos de diversos partidos. Sabe-se que existem vários produtos derivados de petróleo: o gás de cozinha, a gasolina, o óleo diesel, o querosene, o asfalto e a parafina. Na Charge 5, a professora questiona os alunos sobre os produtos que são extraídos do petróleo. Em sequência, seus alunos respondem conforme o esperado, considerando os derivados de petróleo. O inesperado de uma das respostas é propina como uma substância de extração de petróleo.

Para se falar sobre o mundo e para o mundo, utiliza-se das categorizações para se referenciar às ações, emoções, coisas, pessoas que tenham características semelhantes. $\mathrm{O}$ ato de categorizar está ligado à significação assumida por cada pessoa e sua experiência. Então, as palavras petróleo e extração, pelos fatos marcantes vivenciados em nosso país, a significação dessas palavras têm a flexibilidade de serem encaixadas em outra categoria, o da corrupção, 
devido aos efeitos prototípicos.

No caso, os elementos extrair e petróleo são constituintes do $\mathrm{MCl}$ do petróleo como atividade econômica. Esses elementos servem como fonte, pois dão acesso ao $\mathrm{MCl}$ do petróleo como corrupção e levam até ao alvo da metonímia, a propina.

O autor da charge usa o modelo metonímico proposto por Lakoff (1987) exemplos salientes, para mostrar como se estabelece a relação de contiguidade entre a fonte e o alvo. Através desse mecanismo, a menção da palavra propina funciona como elo da característica que representa a corrupção ocorrida na empresa de petróleo para se aludir a um dos produtos extraídos. Esse acontecimento é bem familiar e memorável na história do Brasil, por isso serve como um exemplo saliente. A metonímia conceptual tendo como fonte, a extração de petróleo, e o alvo, a propina, tem as conceptualizações oriundas das experiências cotidianas e das vivências sociais, políticas e culturais de uma comunidade linguística.

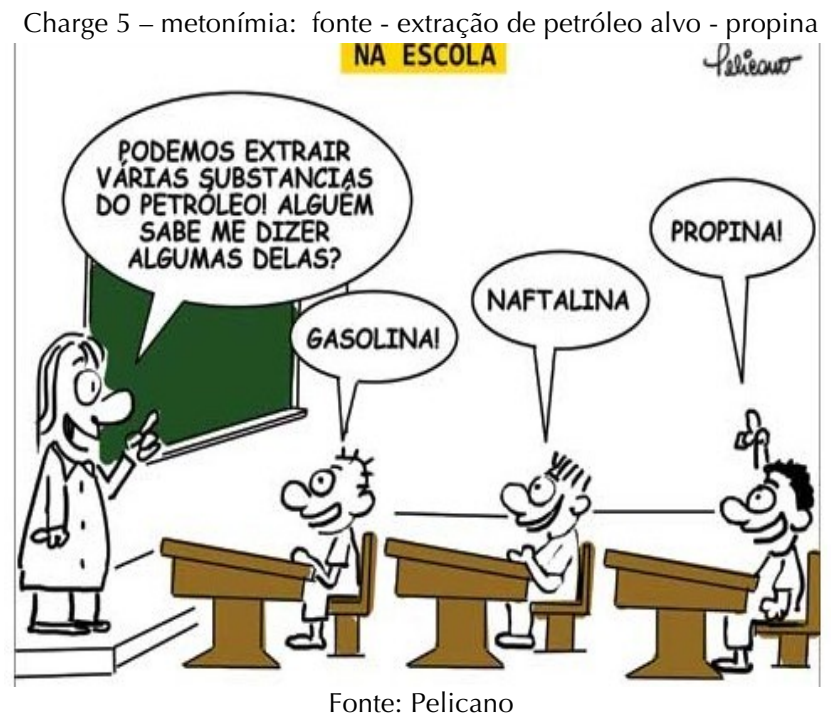

\section{Considerações finais}

Este estudo dedicou-se a apresentar um recorte das possibilidades de análise e interpretação de dados linguísticos que a Linguística Cognitiva traz à tona conciliando os campos semântico e cognitivo.

Com o intuito de se fazer um levantamento sobre o uso impactante e criativo das 
palavras, especificamente de metáforas e metonímias presentes na atualidade, através de textos do gênero charge, assumiu-se a abordagem da linguagem com interações e influências da vivência de mundo dos indivíduos e de suas capacidades cognitivas. Portanto, o foco da pesquisa foi sobre o entrelaçamento das manifestações criativas da linguagem e experiência individual, social e cultural.

Pode-se constatar o uso criativo das palavras em charges que circulam online e que são de fácil acesso para a maioria das pessoas. Isso consta como uma comprovação de que as metáforas e metonímias conceptuais estão presentes em nossa vida cotidiana, numa troca constante, que, ora fornecem, ora retiram, dados linguísticos do meio social e cultural.

Com olhos mais críticos, é possível observar a variedade de metáforas e metonímias conceptuais presentes em nosso dia-a-dia. Focando-se nas charges, um dos meios pelo qual se encontra o uso criativo das palavras, torna-se claro que a categorização é empregada para raciocinar sobre as várias coisas existentes em diferentes universos linguísticos. As metáforas e metonímias empregadas para se compreender um conceito revelam a categoria onde ele se encaixa.

Implementado pela tradição das correntes estruturalista e gerativista no espectro escolar, tem-se a tendência de pensar sobre a metáfora e metonímia somente como recursos de estilo e da retórica. Entretanto, com o advento da Semântica Cognitiva, proporciona-se pesquisas que possibilitam considerar a extensão desses mecanismos pela sua abrangência na perspectiva cognitiva.

Assim, através destas ponderações apresentadas neste estudo, conclui-se que as metáforas e metonímias assumem o estatuto de mecanismos cognitivos como base para a estruturação dos conceitos que formamos sobre as várias coisas de nosso cotidiano. Portanto, os vários conceitos que temos e que se manifestam através das palavras são resultados da rede de fios que carregam nossa experiência e conhecimento individual, além do contexto social, histórico e cultural por onde ocorre esse entrelaçamento.

\section{Referências}

ARISTÓTELES. Arte poética. Texto integral. Martin Claret. Disponível em: $<$ file:///C|/site/livros_gratis/arte_poetica.htm>. Acesso em 04 abr. 2018.

AULETE, Caldas. Aulete digital - Dicionário contemporânea da língua portuguesa:

Dicionário Caldas Aulete, vs. online. Disponível em: <http://www.aulete.com.br $\geq$. Acesso em: 15 abr. 2018. 
BESSINHA. Bessinha, a charge. 07 mai. 2009. Disponível em: <http://blogdobarbosa.jor.br/6109/>. Acesso em: 16 fev. 2018

BIDERMAN, Maria Tereza Camargo. Dimensões da Palavra. Filologia e linguística portuguesa, n. 2, p. 81$118,1998$.

BRASIL. Ministério da Segurança Pública. Disponível em: <http://www.pf.gov.br/institucional/acessoainformacao/institucional/competencias $>$. Acesso em: 10 abr. 2018

BRÉAL, Michel. Ensaio de semântica: ciência das significações. Tradução de Aida Ferras et al. São Paulo: Pontes, 1992

CABRAL, Ivan. Xingamento. 24 ago. 2007. Disponível em: < http://www.ivancabral.com/2007/08/>. Acesso em: 16 fev. 2018

COSTA, Marcos Antonio. Estruturalismo. In MARTELOTTA, Mário Eduardo (Org.) Manual de linguística. São Paulo: Editora Contexto, 2008.

GEERAERTS, Dirk. Theories of lexical semantics. New York: Oxford University Press, 2010.

JOTA A. Charge: e no fim das contas a doença do Brasil se chama corrupção.20 abr. 2015. Disponível em: $<$ https://www.portalodia.com/blogs/jotaa/charge-e-no-fim-das-contas-a-doenca-do-brasil-se-chamacorrupcao-231360.html>. Acesso em: 15 fev. 2018.

KOVECSES. Zoltán. Where metaphors come from. New York: Oxford University Press, 2015.

LAKOFF, G.; JOHNSON, M. Metaphors we live by. Chicago: University of Chicago Press, 1980

LAKOFF, George. Women, fire, and dangerous things. Chicago: University of Chicago Press, 1987.

LILA. $\quad$ sem título].21 de jul. $2008 . \quad$ Disponível em: <https://memorialdeipaumirim.wordpress.com/2008/07/page/2/>. Acesso em: 15 fev. 2018.

MACCAULEY, Robert N. The role of theories in a theory of concepts. In: NEISSER, Ulric. Concepts and Conceptual Development. New York: Cambridge University Press, 1987.

PELICANO. A charge do dia. 18 nov. 2014. Disponível em: <http://blogdobarbosa.jor.br/pelicano-a-chargedo-dia/>. Acesso em: 15 fev. 2018.

SATURNINO, Felipe. Corrupção é eleita a palavra do ano. Jornal O Estadão. 09 nov. 2017. Disponível em: $<$ https://emais.estadao.com.br/noticias/comportamento,corrupcao-e-eleita-a-palavra-do-ano-porbrasileiros,70002077782>_.Acesso em: 15 mar. 2018.

SILVA, Augusto Soares. A linguística cognitiva - uma breve introdução a um novo paradigma em linguística. Revista portuguesa de humanidades, ISSN 0874-0321, Vol. 1, № 1-2, p. 59-101, 1997.

ULLMANN, Stephen. Semântica: uma introdução à ciência do significado. (J. A. Osório Mateus, Trans.) Lisboa: Fundação Calouste Gulbenkian,1964. 